\title{
MODELLING WELFARE EFFECTS OF A LIBERALISATION OF THE DUTCH ELECTRICITY MARKET
}

\author{
ROLF W. KÜNNEKE ${ }^{\dagger}$ and MONIQUE H. VOOGT \\ University of Twente, Faculty of Public Administration and Public Policy, P.O. Box 217, NL-7500 AE \\ Enschede, The Netherlands
}

(Received 22 July 1996)

\begin{abstract}
The Dutch electricity sector has traditionally been dominated by the public sector. Although this organisational structure resulted in a reliable and low-priced system, it is said not to be completely stable and efficient. National and international developments stimulate the introduction of a liberalised system. In this article, we present the model NEDMOD which is used to estimate possible welfare gains of an implementation of a liberalised market system in the Dutch electricity market. (C) 1997 Elsevier Science Ltd.
\end{abstract}

\section{INTRODUCTION}

As in many other countries (i.e. U.S.A., U.K., Norway, Sweden, Finland, Argentina, Chile and Spain), the electricity sector in the Netherlands is undergoing a process of transition from a strongly regulated to a more market-oriented regime. This process has its origins mainly in national developments, but it is speeded up by developments in the European Union (EU) where there is an ongoing discussion about opening up this vital market to competition.

Traditionally, the Dutch electricity industry has been dominated by the public sector and holds a monopoly position. Public authorities own and operate generating and distribution companies. All major allocation decisions, including pricing and investments, are made within a system of central national planning. This system, which was more or less in place by the beginning of this century, has performed well in terms of reliability and (currently) price levels. The Netherlands has now one of the lowest electricity tariffs in the EU. In the discussion about the costs and benefits of a possible liberalisation of the electricity market, this fact is sometimes used as an argument to question the need to reform the sector. However, the present structure of the Dutch electricity sector is no longer considered to be satisfactory, and there are serious indications that the existing institutional framework is both unstable and inefficient[1]. This instability is partly caused by an unexpected growth in investments in smallscale combined heat and power plants (CHP) made by independent power producers (IPPs). These investments became quite profitable for big industrial firms following the introduction of incentives provided for in the Dutch Electricity Act 1989 (EA '89). Industrial firms investing in CHP are able to sell surplus electricity to the grid at a guaranteed price lower than the current market price. These decentralised CHP plants are proving to be very competitive compared with existing large-scale producers; over the past few years, this decentralised generation has gained a market share of about $22 \%$. On the negative side, the success of decentralised CHP plants has resulted in increasing overcapacity, and therefore in higher exploitation costs for the big electricity generators. These central electricity generating companies are obliged to adhere to a system of central planning and pricing, which does not apply to decentralised production by IPPs. It has become evident that either the activities of decentralised IPPs will have to be integrated into the central planning system or the electricity market will have to be liberalised.

Another factor causing instability proved to be a growing conflict of interest between generators and distributors following vertical disintegration of these firms as result of EA '89. Through a process of mergers, the distribution industry acquired some very significant market players able to dominate the electricity generation industry. These big distributors have developed confident strategies and an independent business position. Some of them are looking for opportunities to find new markets for electricity 
outside the existing system, for example, by independently importing electricity or through joint ventures with IPPs.

The presumed inefficiency of the current system has, in part, been revealed by the success of the IPPs, while the big electricity generators failed to grasp fully the opportunities presented by CHP technology. The growing overcapacity has also forced traditional generators and distributors to rethink their investment strategies. The electricity sector and the Dutch Government have initiated several studies on efficiency gains which could be made by reorganising the sector and suggest that improvements are possible $[2,3]$.

We present a model for estimating the expected welfare gains and losses for two policy alternatives: the re-establishment of a system of central national planning with only limited possibilities for decentralised CHP, and a liberalised structure in which prices act as the main co-ordinating mechanism. Liberalisation is the preferred alternative for The Netherlands as far as the expected welfare effects are concerned. The next section provides a brief overview of the structure of the electricity sector up to 1995, which is the basis for the policy alternative of re-establishing the system of central planning. Section 3 is a discussion of a liberalised electricity market. The model used to estimate the welfare effects of both alternatives is outlined in Sec. 4; in Sec. 5, we discuss the way this model has been applied. The main results are summarised in Sec. 6, and some concluding remarks presented in Sec. 7 .

\section{ORGANISATION OF THE DUTCH ELECTRICITY MARKET TO $1995^{\dagger}$}

Figure 1 illustrates the general institutional framework of the Dutch electricity sector up to 1995 , producers and distributors having been vertically disintegrated by EA ' 89 . The four main producers co-operate in SEP ${ }^{\ddagger}$, which pools all electricity generated nationally and is responsible for both the technical and economic aspects of its delivery, as well as for the import and export of electricity. In order to secure long-term supply of electricity (investment in new power plants and decommissioning old ones), the generating companies draw up joint national plans every 2 years. These have to be approved by the Ministry of Economic Affairs. This Electriciteitsplan is binding upon the four generating companies and SEP.

The central co-ordination of electricity generation is very rigidly organised. On the basis of a production cost optimisation program, SEP informs the generating companies which power plants are to be used to generate electricity. Regional surpluses are transferred by SEP to generating companies in regions with a shortfall. The benefits of this procedure are divided among the generating companies via the cost-pooling system which leads to uniform production costs, and the benefits from import and

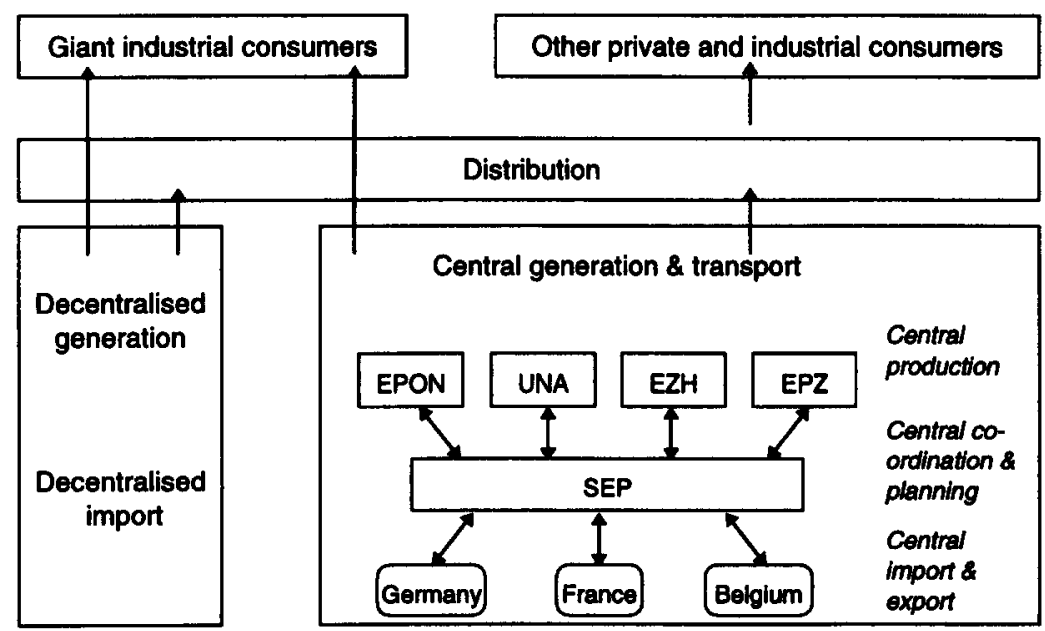

Fig. 1. Structure of the electricity sector in the Netherlands.

\footnotetext{
'For a more detailed description of the Dutch electricity sector, see for example Ref. [4]. The second and third paragraphs of our article draw heavily on this source.

‡This abbreviation stands for the Dutch Electricity Generating Board (Samenwerkende Electriciteits Producenten)
} 
export transactions are distributed in the same way. As the distributors are legally excluded from import and export activities, SEP has a de facto Dutch monopoly in the international trade in electrical power.

Figure 1 illustrates that a share of the electricity consumed is not centrally generated or imported, which is permitted by EA ' 89 . Giant industrial consumers have free access to international electricity markets, although none of them have made use of this right so far because they have to pay substantial charges for using the national grid. Distributors are allowed to produce electricity in plants with a capacity below $25 \mathrm{MW}$ installed power. Industrial companies, though, have the legal right to generate electricity without any limitation on the size of their generating capacity. Distributors are obliged to buy this surplus electricity at a fixed price which is cost-effective. As mentioned above, this decentralised production capacity interferes with the national production plans made by the four big generating companies united in the SEP, thereby exacerbating the problem of overcapacity at the national level.

There are 35 distribution companies. Most of them distribute not only electricity but also supply natural gas for residential heating, district heating, and central cable services for radio and television; eight distribute only natural gas. In 1993, the distributors delivered electricity to some 6.7 million customers; that same year, households took about $18,000 \mathrm{GWh}$ and industry about $26,000 \mathrm{GWh}$ of electricity. Distributors buy electricity from their regional generator at the national pooling price plus the costs of transport and delivery incurred by the generator. Legally, distributors are allowed to buy electricity from a producer of their choice within the territory of The Netherlands. This opportunity is not effective and therefore not used because of an absence of effective price differences. Recently, several large industrial consumers have used their legal rights to generate electricity, not only for their own use but also to meet substantial contracts made with local distributors. Several distributors have established joint ventures with industrial partners in order to build up a decentralised capacity, which in all cases consists of CHP. This decentralised generation has gained a significant market share of about $22 \%$ of national electricity consumption. This success has loosened the tight relations which united the generating and distributing companies in the Dutch electricity sector. Although the amount of decentrally generated electricity is still limited, decentralised generation is the first serious challenge to the electricity generation monopoly enjoyed by the SEP. Recently, CHP has received substantial social (and public financial) support for environmental reasons, further chipping away at large-scale electricity generation by SEP in favour of investments in CHP made by the distributors.

\section{THE PROPOSED REFORM}

The Dutch Government has recently produced a policy document on the liberalisation of the electricity market as a blueprint for the future structure of the sector [5]. Although this proposal is of a quite general nature, it provides interesting insights into the possible direction of future developments. In the document, the Government proposes generally free access to the electricity grid based on nondiscriminatory conditions. However, this right of free access will be granted to different groups of customers during different periods of time. Three groups of customers have been identified: first, captive customers, which consume less than $50,000 \mathrm{Kw}_{\mathrm{e}} \mathrm{h} / \mathrm{y}$. These are customers of the regional distributors as natural monopolists. This customer group is last in line for access to the grid. Second, an intermediate group of customers, with electricity consumption between 50,000 and 10 million $\mathrm{Kw}_{\mathrm{e}} \mathrm{h} / \mathrm{y}$. This group will remain captive customers for a maximum period of 5 years. Exemptions for earlier access may be possible in the coming period. Third, very big industrial consumers which consume more than 10 million $\mathrm{Kw}_{\mathrm{e}} \mathrm{h} / \mathrm{y}$. This group has immediate access to the grid. Free-access customers are free to select the electricity generating company or trader of their choice. In this market segment, the price mechanism is assumed to guide economic activities.

The captive customers and the intermediate group are provided with electricity by the existing distribution companies, which are legally obliged to serve them. Distribution companies are free in their choice of electricity supplier, and therefore may also become involved in direct international trade. Captive customers will be protected in several ways, by ensuring security of supply and regulating tariffs. In this market segment, the controlled self-regulation of the present system will be more or less continued. However, the Government is seriously minded to reduce the size of this market segment, and finally grant free access to all consumers. It is proposed that the four existing electricity generating companies merge to form one big company. This is considered necessary in order to create a stronger 
position for the Dutch electricity generating sector in the anticipated liberal European market. This national electricity generating company will be organised as a private stock company, which has, like the current companies, only public entities as stockholders. The overall conclusion is that the Dutch Government is genuinely interested in liberalising the electricity market for all groups of customers.

\section{THE NEDMOD MODEL}

A mathematical programming tool is needed to quantify the possible consequences of different institutional arrangements for the Dutch electricity market. For this analysis, we developed the NEDMOD model. NEDMOD is a non-linear programming model based on the Nordic energy market model NORDMOD[6] which was developed at Statistics Norway to analyse the electricity 'market in the Nordic countries. NEDMOD is a partial equilibrium model that focuses on the generation and final use of electricity in The Netherlands and the countries with which there is significant international electricity trade. This section starts with a description of the choice of model in light of the requirements of the underlying study. Sections $4.2-4.7$ continue with a description of the NEDMOD model.

\subsection{Choice of model}

The NEDMOD model developed for the underlying study had to be a long-term model that could be used for analysing changes in the structure of the Dutch electricity supply market, for example, by introducing more competition, or introducing new or improved electricity generating technologies. Energy-economic modelling in general distinguishes between engineering process models and econometric models. Because of their high dependency on time series data the latter are better suited to shortterm forecasting than to long-term forecasting. Furthermore, econometric models cannot be used for analysing the introduction of new technologies, since there are no appropriate time series available. Engineering models are built on a detailed description of energy flows and the technological options and potentials in the energy system, and therefore are better equipped for our purposes.

Like almost all long-term energy-economic models, NEDMOD is based on traditional neo-classical theory: consumers are assumed to strive for maximisation of individual utility, and producers for maximum profits. Prices are determined by a general Walrasian economic equilibrium for a system of competitive markets. Looking at the scope of long-term equilibrium models, we can distinguish several types of models, ranging from general equilibrium models incorporating all energy markets and comprising a complete macro-economic submodel, to partial equilibrium models of one energy sector or one type of fuel.

Computable general equilibrium (CGE) models such as the Bergman [7], DGEM [8] or GREEN [9] models, provide a very complete form of modelling long-term energy-economy interactions but are not suited to our purposes. CGE models are based on the use of sector-level production functions in which capital is treated homogeneously; as a result, the economy is described on a highly aggregate basis, and it is not possible to distinguish between different types of technology. If the aim of the study is to analyse one specific part of the energy sector or just possible future trends, it is often not necessary to develop economy-wide models. Very often, it is enough to develop a partial equilibrium model in which (a part of) the energy sector is described in full detail, using exogenous values for energy demand growth and sectors of the economy otherwise not considered. A drawback is that this type of model fails to analyse the effects of changes in (a part of) the energy sector on non-energy sectors and, if only a part of the energy sector is modelled, on other energy sectors. The advantage is that these models contain much more detail on supply technologies and/or demand patterns. Partial equilibrium models are mainly used for scenario analyses in which the outcomes of implementing various policy options are compared with those of some reference case. Well-known examples are MARKAL [10], models from BNL, such as BESOM and TESOM [11], the Edmonds-Reilly model [12], and the Regionalized Electricity Model (REM) originally developed by Baughman and Joskow [13].

Another type of model we would like to mention are integrated models, or integrated modelling systems, which have become very popular in recent years. Integrated modelling systems link existing econometric, optimisation and energy sector models, providing the basis for a complete analysis of energy policy options. Some well-known examples of these systems are ETA-MACRO [14], MARKAL-MACRO [15], the HJ-BESOM model, later named the LITM-BESOM model [16], the 
IIASA model system [17] and IFFS [18]. ${ }^{\dagger}$ Although this type of model would serve the goals of this study very well, its time-intensity and complexity made us choose another.

Since this study was aimed at quantifying the direct consequences of changes in the structure of the Dutch electricity supply market, we were able to confine our efforts to the development of a partial equilibrium model. Limiting the scope of the model enabled electricity generating technologies and the description of electricity demand to be modelled at a high level of detail. Specific Dutch data were used for the description of the economic and technical aspects of available electricity generation technologies. The fact that NEDMOD is a partial equilibrium model of the electricity market implies that other energy sectors and non-energy sectors of the economy are taken to be invariant under changes in the electricity sector. The impact on the electricity market of changes in other markets is accounted for in the model by exogenous figures on total production or consumption, energy efficiency, prices of substitutes and a number of elasticities. Unlike many other models, international trade is not described by incorporating exogenous parameters on, for example, the world market price for oil but rather by including endogenous variables for trade with some neighbouring countries.

NEDMOD consists of four blocks which describe different aspects of the electricity market. The two most important blocks are the descriptions of the demand for and supply of electricity. As is discussed in more detail in this section, demand functions are defined for different groups of consumers. Supply functions are derived by estimating the marginal costs of different production technologies. By calculating equilibrium prices under different institutional arrangements, national welfare can be estimated as the sum of consumer and producer surpluses. The two other blocks describe international trade and include certain government-imposed restrictions on the electricity market, including environmental policy targets and limitations on access to markets. The different components of the model are described in detail in the following sections of the paper.

\subsection{Description of demand}

Total demand for electricity is calculated as the horizontal sum of the individual demands of several groups of end-users. The demand for electricity from a certain group of end-users in a particular year is described by the following Cobb-Douglas-type function:

$$
D(i, j, k)=A(i, j) P e(i, j, k) e^{p(i, j)} P g(i, j, k) e^{p x(i, j)} Y(i, j, k) \epsilon^{(i, j)},
$$

where for the group of end-users $j$ in country $i, D=$ demand for electricity in year $k, A=$ constant, $P e$ $=$ price of electricity in year $k, P g=$ price of gas in year $k, Y=$ expected level of production or income, corrected for energy-efficiency changes, $\epsilon p=$ direct price elasticity, $\epsilon p x=$ cross price elasticity between electricity and gas, and $\epsilon y=$ elasticity of income or production. In the Netherlands, NG is the most important substitute for electricity. For this reason the gas price and the cross price elasticity between electricity and gas is considered in the demand function (for a further elaboration of this point, see Sec. 5.3).

\subsection{Description of supply}

In the model, total supply of electricity is defined as the total amount of electricity needed to satisfy demand. The total supply calculation is based on the use of technologies available for electricity generation, and so no distinction is made between different supply companies. There are two reasons for this choice. First, modelling all existing supplying companies would involve an enormous problem of analysing the data since it would be very hard, if not impossible, to gain enough understanding of the price components of all the suppliers. Second, in this analysis we are not interested in who produced the electricity consumed but how this electricity is generated.

In the model, we make a distinction between the production units used at the start of the simulations and production units built during the simulations. The capacity and remaining lifetime of the existing units is predefined, and the investment costs of these units are regarded as 'sunk costs', the supply of electricity by these units depends only upon variable costs. Expansion of production capacity can take place by building new units using technologies already in use or by introducing a new technology.

${ }^{+}$The Intermediate Future Forecasting System (IFFS) was used for national US energy forecasting until 1993, when it was succeeded by the National Energy Modelling System (NEMS). 
Whether expansion takes place or not depends on the calculated price of electricity; if this price is higher than the long-term marginal costs of the cheapest new production unit, then investments will be made. The depreciation costs of new units are calculated using the annuity method.

\subsection{International trade}

The NEDMOD model can be used for calculations either with or without the possibility of international trade. Where international trade is allowed, a distinction is made between neighbouring countries (as the most important regions for possible free international trade) and 'other countries' of marginal economic importance. For these 'other countries', an exogenous value for net exports (or imports) is included in the model. Market conditions in countries with relevant trade relations are simulated endogenously by the model. For the Dutch case, the electricity markets in Germany, France and Belgium are modelled in detail, including international trade relations. For these countries, a description of existing production units, current electricity prices, current and expected demand for electricity, and possible increases in production capacity are included in the model. Furthermore, existing transmission capacity between the Netherlands, France, Germany and Belgium, as well as the costs of new transmission capacity (split between investment costs and variable costs per $\mathrm{KWh}$ ), are introduced exogenously in the model.

\subsection{Policy restrictions}

Electricity markets are traditionally heavily regulated. The provision of electricity is considered to be a public task that has to meet certain public policy objectives, and regulation of the electricity industry is often used to influence economic activities in other sectors. A well-known example is the German Kohlepfennig, a levy on the electricity price which was used until 1995 to subsidise the local mining industries. In order to allow for significant government intervention in this sector, certain restrictions have been included in the model as a fourth building block. For the specific case of The Netherlands, the following aspects are relevant (see also Ref. [3]): (i) security of national supply (definition of a minimum total national production capacity); (ii) protection of the national electricity sector (which is translated into limits to international trade); and (iii) fuel diversity or stimulation of the use of certain technologies (definition of upper or lower limits to the total available or used capacity using specified technologies).

Another aspect of public policy which can be included in the model, but is not used in the present simulations, is environmental policy. Electricity generating companies in the Netherlands, as well as in other countries, have to meet certain environmental standards. NEDMOD can be used to analyse the consequences of different environmental policies. The model is able to calculate $\mathrm{CO}_{2}$ emissions per unit of fuel used. By multiplying this so-called $\mathrm{CO}_{2}$-emission coefficient for a certain type of fuel by the total amount of that fuel needed, and adding these up for all types of fuels, we can calculate total $\mathrm{CO}_{2}$ emissions resulting from electricity generation. In addition to $\mathrm{CO}_{2}$ emissions, NEDMOD also includes a registration of $\mathrm{NO}_{x}$ and $\mathrm{SO}_{2}$ emissions. Since these kinds of emissions strongly depend upon the technology used, we defined $\mathrm{NO}_{x}$ and $\mathrm{SO}_{2}$ emission coefficients per unit of electricity generated for every technology included in the database. By multiplying these coefficients by the total amount of electricity generated per technology, and adding this up for all technologies used, the total $\mathrm{NO}_{x}$ and $\mathrm{SO}_{2}$ emissions can be calculated.

\subsection{Calculation of equilibrium price}

The model determines the electricity price endogenously by equating total electricity demand to total electricity supply. The electricity price $(P e)$ has different components: the cif-price which includes transportation and insurance costs ( $P$ cif); running costs, for example, for transmission and distribution $(B)$; charges $(H)$; and (only for households) value added tax $(T)$. In order to allow for different pricing policies with respect to different groups of consumers, a price discrimination factor $d(i, j)$ has been defined for groups of end-users $j$ in country $i$. Hence, the electricity price in a certain year is calculated from

$$
P e(i, j)=[P c i f(i, j)+B(i, j)+d(i, j)+H(i, j)][1+T(i, j)] .
$$

Without allowing for international trade, the equilibrium price for electricity is calculated by setting 
the total national supply of electricity equal to the total national demand for electricity. When allowing for the possibility of international trade, the equilibrium price is derived by equating the total amount of electricity generated nationally, plus imports to the total national demand for electricity,plus exports. Given the current demand and current electricity prices, the model calculates the equilibrium price for a certain year. If the existing capacity cannot meet total demand, expansion of production capacity will take place. As explained above, expansion will also take place in a situation where the calculated equilibrium price for electricity exceeds the long-term marginal costs of a new technology. For the following year, the calculated electricity price and the demand functions are used to determine the new value of total demand for electricity. By equating the new total demand with the new total supply a new equilibrium price is calculated, and so on.

\section{THE CASE OF THE NETHERLANDS}

A number of simulations were carried out in order to calculate the possible welfare effects of different institutional structures for the Dutch electricity sector. Basically, two different regimes were compared. First, re-enforcement of a system of national planning. This scenario is essentially a continuation of current arrangements in the sector, in which decentralised production capacity is strictly limited by the system of national planning (Electriciteitsplan). Second, liberalisation towards a free-market-oriented system, with price acting as the dominant allocation mechanism. In this scenario, we tried to model the basic ideas of the reform proposal. Both scenarios are described in more detail in the following sections, after which the results of applying the model to a specific case are described. The availability of data led us to choose 1993 as the baseline year for the simulations, which end in the year 2010.

\subsection{Re-enforcement of a system of national planning}

In the first scenario the system of national planning is re-enforced. Throughout the whole simulation period all official plans from the SEP published in the Elektriciteitsplan 1995-2004 (E-plan) [19] are assumed to be binding and they are, if necessary, extrapolated to the end of the simulation period. As in the current situation, decentralised production units will not be covered by national planning, but we assume the maximum capacity will be that mentioned in the E-plan. As far as international trade is concerned, the current situation in which only SEP imports electricity, at a level of under $15 \%$ of national demand, will be maintained. Existing import contracts mentioned in the E-plan will be respected; further international trade will be severely restricted.

\subsection{Liberalisation}

In the 'liberalisation' scenario, it is assumed that supply and demand in the electricity market is coordinated primarily by the price mechanism. This scenario represents the expected long-term organisational structure of the Dutch electricity sector, and is based on the current proposals. The route towards this situation has not been modelled; the opening up of the market to different groups of consumers is assumed to have been completed. Essentially, free market entrance is guaranteed and there is competition between market players. New production units will only be built if the existing production capacity falls short of total demand, or if the total marginal costs of new technology are lower than the variable costs of existing plants. Given certain public policy restrictions included in the model, expansion of capacity will involve the cheapest available technology.

In the 'liberalisation' scenario, foreign producers will also have free access to the Dutch market. Free competition with domestic suppliers will be possible and will depend upon the price of electricity. We assume that this will also be the case for Dutch suppliers to foreign markets. The 'liberalisation' scenario allows the expansion of domestic production capacity to meet the potential demand for exports. However, in this open market system the Government might want to act to protect its national interests by restricting the volume of certain trade flows or by realising national or international environmental goals; these can be included in the model by defining relevant policy restrictions.

\subsection{Implementation of demand}

Natural gas is identified as being the most important substitute for electricity in the Netherlands, although heat has also become an important substitute in recent years. The price of gas is exogenous 
to the model and is directly calculated from the estimated world market price for oil. Demand functions are modelled by defining exogenous parameters for the price of electricity and gas in the baseline year, the expected total production or total income for every year in the simulation period, and a number of elasticities. Furthermore, data on the price components of electricity and gas, such as charges and taxes, the expected gas price, and an indication of the level of technological innovation are included.

Five groups of electricity consumers are identified in accordance with the classification used by official bodies in the Netherlands. These consumer groups are: large industrial users, other industrial users, public transport, households, and other activities (e.g. services). For the description of consumer groups in France, Germany and Belgium, only industry and households have been distinguished as separate groups.

\subsection{Implementation of supply}

For implementation of electricity supply, the model contains a description of technologies available during (a part of) the simulation period. Most electricity in the Netherlands today is generated by using organic fuels (i.e. coal and gas). In the model, the most important types of production units are included, namely, coal-fired plants, conventional gas-fired units, combined cycle technologies, and solo gas turbines. Electricity generation technologies other than those based on the use of organic fuels, such as wind power, nuclear power, water power, photovoltaic systems, and waste incineration, are also defined in the model.

The technologies are described by several technical and economic characteristics. Economic data include investment costs, fuel prices, and operating and maintenance costs. Technical data include fuel efficiency coefficients, potential capacity, lifetime and operating hours of the available technologies. Each technology is defined in the same way for all simulations; only the maximum or minimum level of available capacity may differ. In NEDMOD we make a distinction between costs which are independent of the amount of electricity generated, fixed costs, and costs that vary with production, variable costs. Fixed costs consist mainly of investment costs, and are depreciated in the model by using the annuity method; as a result, the yearly fixed costs per megawatt are constant. The variable costs consist of fuel costs, operating costs, (environmental) levies, and distribution and transport costs. The database also contains a scenario for future fuel prices per country.

Some additional restrictions were included in the model for simulating the 're-enforcement of a system of national planning' scenario. First, planned coal-fired and gas-fired units were added to the existing central capacity. For some technologies, this meant enforcing the use of a minimum amount of capacity in the model. Second, in accordance with the current policy of the SEP, a condition was added to ensure that a certain minimum percentage of total capacity consists of coal-fired plants. Third, the prognoses for the level of decentralised CHP capacity in the E-plan is used as a proxy for the upper limit on CHP capacity used to generate electricity.

\subsection{International trade}

The current situation in the neighbouring countries of Germany, France and Belgium is described in reasonable detail. As in the description of the Dutch electricity market, information on current and future demand, existing and future generating capacities, and some information on public policy restrictions, are processed. In order to be able to model international trade, information on existing transmission capacities, the costs of expanding these capacities, and the variable transmission costs, are also included. As for all data on transmission capacities, transmission costs are exogenous to the model.

Although all the exogenous data are the same in all model scenarios, there are some differences in the opportunities for international trade. In the 'liberalisation' scenario there is free trade, while in the 're-enforcement of a system of national planning' scenario Dutch imports and exports are severely restricted by current policy. These restrictions are imposed by setting an upper limit to the total amount of imported or exported electricity, depending upon total domestic demand and supply. Existing import and export contracts are respected in all the scenarios. For the Netherlands, this implies that contracts for importing electricity from Germany, France and Norway will be honoured.

\subsection{Policy restrictions}

The following policy restrictions are included in the scenarios for the Dutch example. First, security of supply-in order to secure the availability of electricity at any time, a certain reserve capacity has 
to be guaranteed. This reserve capacity is needed in order to cope with swings in demand, as well as calamities and maintenance work. This aspect has been taken care of in the model by adding an extra percentage to all capacities used. In other words, if for a certain technology $T$, a capacity $C_{T}$ is required for production and the percentage of reserve capacity is equal to $s$, the total capacity needed is equal to $(1+s \%) C_{T}$. Second, fuel diversity - in the Netherlands most electricity is generated by gas-fired plants because of the substantial national gas reserves. The electricity sector and the Government have developed a common policy of fuel diversification in order to avoid excessive dependence upon one type of fuel. To meet this fuel diversification policy, a restriction is added which sets a maximum limit to the percentage of gas-fired electricity generating capacity. Third, nuclear power-the Dutch Government has decided that all existing nuclear power units in the Netherlands are to be closed down after the year 2003. We have included this decision in the model by setting the upper limit of existing nuclear power capacity equal to zero from the year 2004. Furthermore, we did not allow any new nuclear power units to be built before the year 2010 (the final year of the simulation period). Importing nuclear electricity, for example from France, is allowed during the whole simulation period.

In this case study, we did not use the possibility of analysing the environmental aspects of electricity generation. The main reason for this decision was that the study was focused on other aspects. Besides, most so-called 'green technologies' are barely used in the Netherlands at the present time, implying that accurate data on, for example, operation and maintenance costs will be lacking. Consequently, the policy to develop and extend the generation and use of sustainable energy is left out of this case study. It would, however, be interesting to carry out some simulations in which emission targets are set and enforced. Implementation of a policy in which emissions have to be reduced could lead to a shift from the use of conventional and more polluting technologies to less polluting 'green' technologies.

\section{SIMULATION RESULTS}

The main objective of this case study is to compare the expected welfare effects of two different institutional arrangements for the Dutch electricity market, as specified in the previous section. This section presents the results of the simulations. Three aspects are highlighted: the choice of production technologies under different institutional arrangements; the development of total demand and supply under different conditions; and the expected relative welfare effects of both scenarios.

\subsection{Type of generation technology}

The possible welfare effects of different institutional arrangements may result from the different technological preferences of the two regimes discussed in this article. Recall that a liberalised electricity market always chooses the cheapest technology on offer (given certain policy restrictions), whereas the 're-enforcement of the system of national planning' scenario leaves more room for political considerations, which are not always necessarily in line with economic reasoning.

The yearly contributions to total electricity generation by all available technologies in the Netherlands $s^{\dagger}$ have been calculated, the contributions from existing and new technologies being aggregated into five groups (from top to bottom in the figures presented): combined heat and power generation (CHP), coal-fired plants, other gas-fired plants, nuclear units, and sustainable or 'green' technologies.

Figure 2 presents the contributions made by these groups of technologies in terrawatt-hours for the 're-enforcement of a system of national planning' scenario.

It is evident that the importance of CHP capacity within the total amount of electricity generated drops in the first years of the simulation. This is a direct consequence of the assumption made in this scenario that CHP capacity is restricted, and that central electricity production takes priority over decentralised production. In this scenario the use of central coal-fired plants is preferred to the use of decentralised CHP, even though the latter is more economic. The available (decentralised) CHP capacity will not be used completely, since in the baseline year there is a significant surplus of available central capacity in the Dutch electricity sector. In later years, the contribution made by CHP increases as a result of an increase in Dutch demand for electricity and the decommissioning of some old conventional plants.

\footnotetext{
${ }^{+}$This analysis concerns total domestic electricity generation, which is not necessarily equal to total national consumption. To obtain total national consumption in the Netherlands, one must add total net imports to the total national production. 


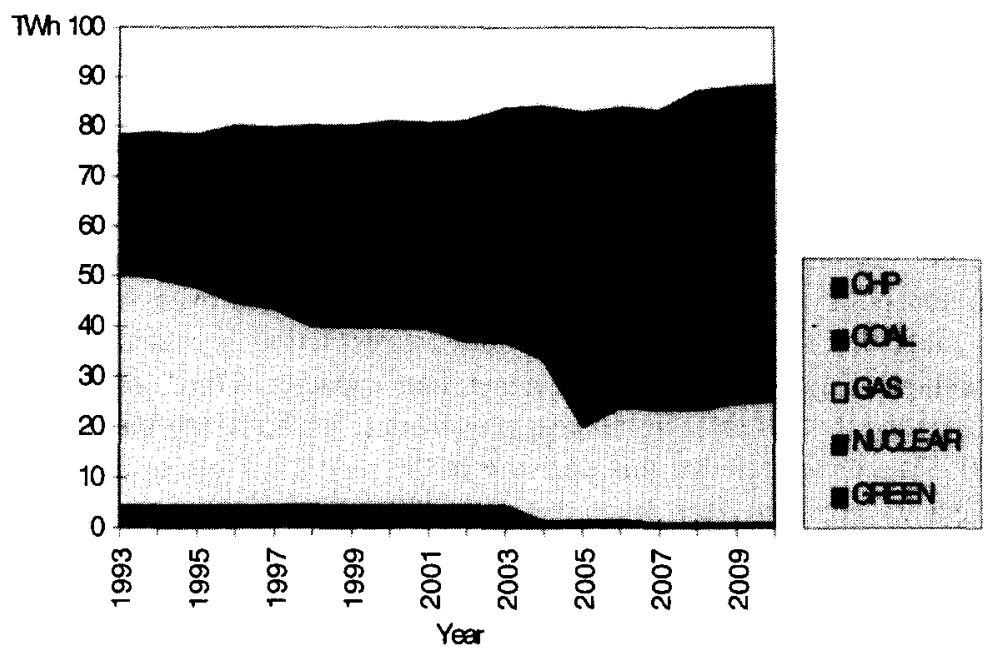

Fig. 2. Composition of the Dutch electricity generation park in the 're-enforcement of the system of national planning' scenario.

The choice of technology is significantly different when the liberalisation scenario is implemented. In this scenario, there is considerable potential for the use of CHP. In fact, the use of CHP is only restricted by setting a yearly limit to the total installed CHP capacity and to the growth of this capacity. Figure 3 shows that the potential for CHP is indeed realised in the market: liberalisation results in a significant growth in the amount of electricity generated in CHP-plants.

Besides indicating a substantial difference in the utilisation of CHP, the figures also reveal an interesting difference in the use of coal-fired plants. Unlike the first scenario, the liberalisation scenario does not contain restrictions on the amount of coal-fired capacity. Figure 3 indicates that the contribution of coal-fired plants to total Dutch electricity generation decreases slowly over the years. Existing coalfired plants are no longer preferred to decentralised CHP. Installation of new coal-fired plants only takes place because this is planned for in the current E-plan fuel diversification policy.

Looking at the figures, we can see that in both scenarios there is no investment in 'green' technologies. This is obviously strongly influenced by the decision not to incorporate any restrictions in the model to control emissions resulting from electricity generation. However, it also indicates that without (extra) subsidies these technologies seem unable to compete on purely economic grounds with conventional technologies.

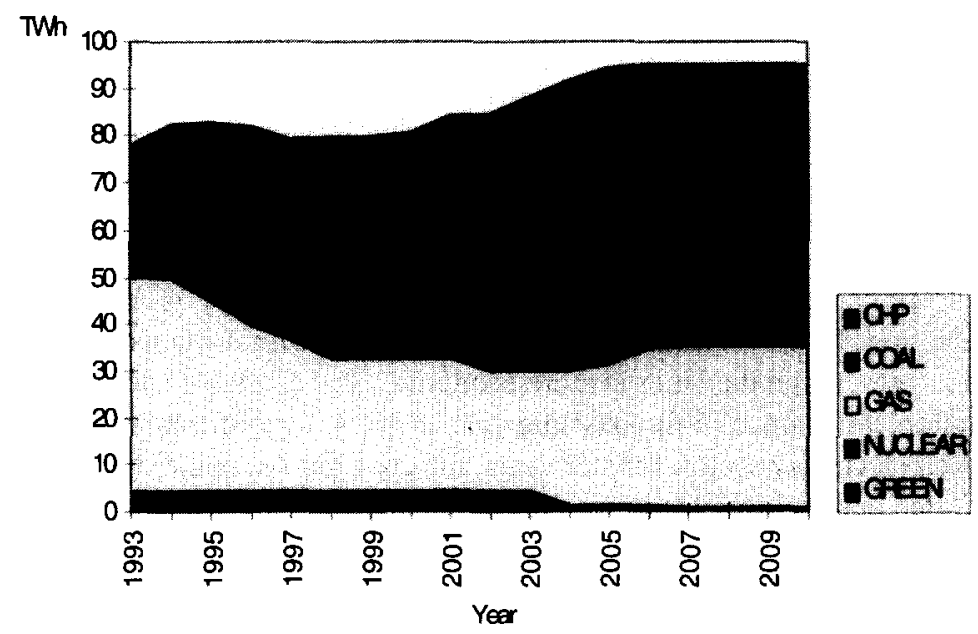

Fig. 3. Composition of the Dutch electricity generation park in the 'liberalisation' scenario. 


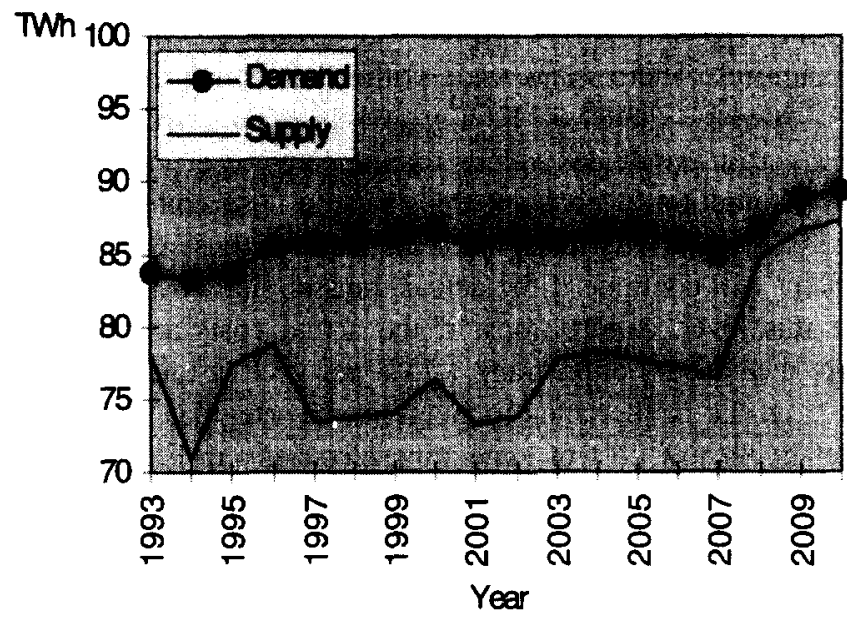

Fig. 4. Total demand and supply of electricity in the Netherlands under the 're-enforcement of the system of national planning' scenario.

\subsection{Total demand and supply}

By comparing the total national demand for, and supply of, electricity it is possible to get an indication of the effects of different institutional arrangements on international trade relations between the Netherlands and its neighbouring countries. Figure 4 illustrates the development of total demand and supply for the 're-enforcement of the system of national planning' scenario. It is evident that the Netherlands will remain a net importer of electricity under these conditions: demand exceeds supply in all years. Since the model must satisfy all demands, this difference must be compensated for by (net) imports of electricity.

The simulation results for the 'liberalisation' scenario show quite a different picture. Figure 5 shows an excess of supply over demand starting in the year 2003. Since it is assumed that no electricity is generated unless demand is not fully satisfied, this implies that from this moment on the Netherlands acts as an electricity exporting country. In order to analyse this very important shift from applying a rigid trade policy with rarely any exports to being a net exporter, we will take a closer look at international trade flows.

As previously mentioned in Sec. 4.4, two kinds of international trade have been distinguished in the model. First, there is the possibility of free trade between the neighbouring countries Germany, France, Belgium and the Netherlands. Second, for each of these four countries, an exogenous value is included to describe the net imports or exports from other countries. In any case, existing export contracts are respected. For the Netherlands, this means that both scenarios include guaranteed imports from Germany

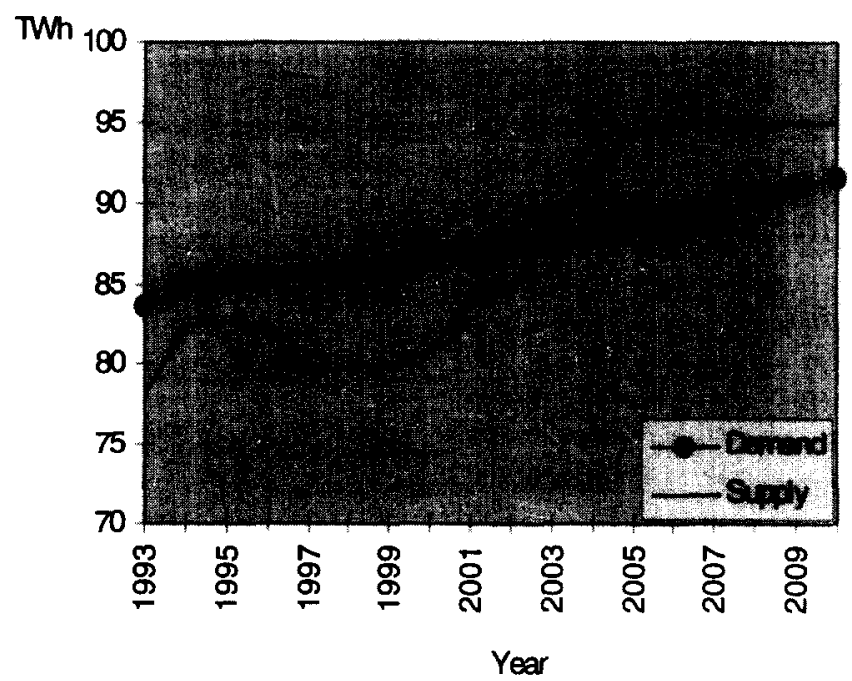

Fig. 5. Total demand and supply of electricity in the Netherlands in the liberalisation scenario. 
(until 2006), France (from 1997 until 2008) and Norway (from 2001 until 2026), and allows additional free trade with these countries. There is no trade with other countries. The simulations indicate that under the 'liberalisation' scenario there will be a growth in exports from the Netherlands to Germany.

The model contains a set of exogenous values for the costs of electricity transmission, but because of the somewhat crude assumption of constant transmission costs, international trade flows cannot be estimated very accurately. A sensitivity analysis of the level of these costs leads to the conclusion that Dutch exports to Germany will continue if the actual transmission costs are up to $10 \%$ higher than the estimated costs; above this level, export stops. If the actual costs are $10 \%$ lower, exports from the Netherlands to Germany increase by on average $1.75 \%$ per year (a total of $19 \%$ over the whole simulation period). Exports from the Netherlands to Belgium are irregular. There are no exports to France at all because of the relatively low cost of generating electricity in France.

\subsection{Welfare effects}

This study focused on obtaining an indication of net welfare effects, and this was achieved in both scenarios. The welfare effects of both scenarios, measured as the sum of producer and consumer surpluses, are compared. The calculated value for total welfare proved to be strongly dependent upon how both the scenarios are interpreted and the values of the parameters included in the model. Since there was some uncertainty about the exact values of some price components, we chose not to calculate the value and development of total welfare for each scenario but to analyse the differences between the scenarios. The advantage of this approach is that possible errors per unit of electricity in the calculation of total consumer and producer surplus are the same in both scenarios, thereby making comparisons valid.

Figure 6 illustrates the difference between the level of total welfare when comparing the two scenarios, as well as the average difference over the whole simulation period. The difference in welfare in the baseline year of simulation (1993) is zero since the model is calibrated for this year.

The 'liberalisation' scenario for the Dutch electricity sector results in a positive change in welfare compared with the situation in which the system of central national planning is re-enforced. The expected average welfare gains of liberalisation are estimated at about 0.4 billion guilders per year. With an annual turnover of about 10 billion guilders in this sector, this amounts to almost $4 \%$ per year. The most important factor explaining the significant welfare benefits to be gained in the 'liberalisation' scenario is a better use of the most efficient technology (in this case combined heat and power generation) in a liberalised market. The second important factor is the utilisation of the possibilities for international trade in a liberalised market. There are also strong indications that the degree of overcapacity is lower in the 'liberalisation' scenario.

In addition to the general welfare gains, Fig. 6 shows a rise in welfare gains in the first years of the simulations. This rise can be largely explained by the existence of a significant overcapacity in the Dutch electricity generation sector at the start of the simulations. Since decentralised electricity generation is

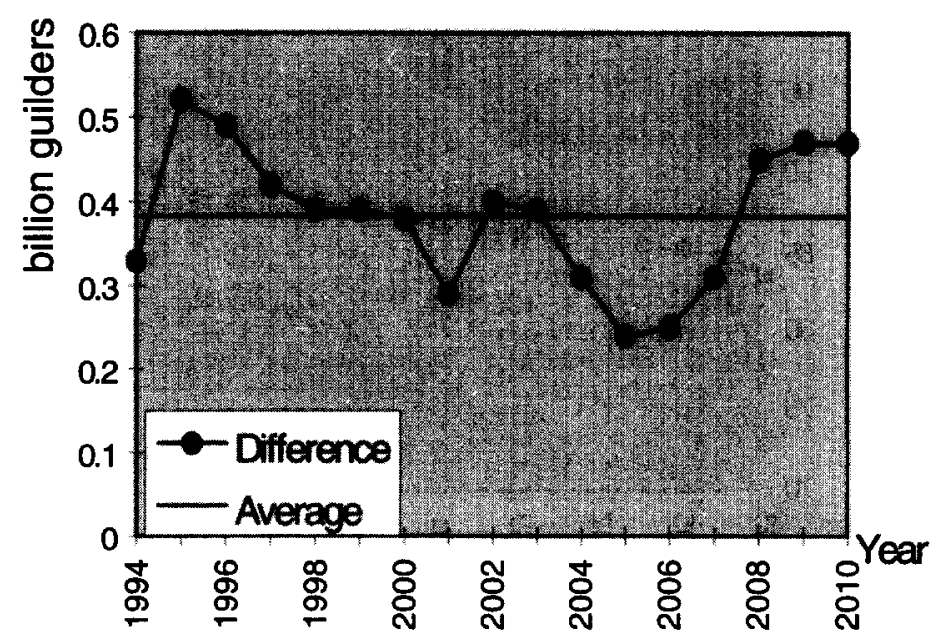

Fig. 6. Difference and average difference in total welfare. 
strictly limited in the 're-enforcement of the system of national planning' scenario, existing CHP plants are crowded out by new, and more expensive, central (coal-fired) units. Replacement of existing capacity and extension of total capacity in the 'liberalisation' scenario is only driven by the economic lifetime of the production units. Implementation of the market mechanism results in lower production costs and therefore higher welfare gains.

\section{CONCLUSIONS}

This article quantifies the possible welfare effects of two different institutional arrangements of the Dutch electricity market, using a partial equilibrium model which estimates the expected welfare under both alternatives. A scenario of 're-enforcement of the system of national planning' is compared with a situation in which demand and supply activities are completely co-ordinated by the price mechanism ('liberalisation' scenario). In order to be able to allow for certain public policy objectives, some restrictions are included relating to security of supply, preferred production technologies, and fuel diversification.

The simulations illustrate that, compared with a 're-enforcement of a system of national planning', implementation of the 'liberalisation' scenario results in net welfare gains of about $4 \%$ of total annual turnover in the Dutch electricity sector. Two main factors have been identified which explain these significant differences in economic welfare resulting from the scenarios. First, under market conditions ('liberalisation' scenario) the most economic technology is chosen. Second, a liberal regime provides better opportunities for international trade. In the 'liberalisation' scenario, the Netherlands becomes a net exporter of electricity, while under current conditions about $10-15 \%$ of its electricity supply is imported. The 'liberalisation' scenario also tends to result in reducing overcapacity. In the scenarios, a significant change towards decentrally produced CHP will be realised under a liberal organisational structure for the sector. About one-half of the supply is produced by this technology. This technical structure of relatively small-scale, decentralised production units fits very well into the conditions which have to be met in order to achieve effective competition within a liberal regime. Whether this is a coincidence or not is another research problem not addressed in this article. The NEDMOD model, which was used to calculate the welfare effects, seems to lead to interesting results. However, it should be emphasised that, like many models, it has some serious limitations. First, it is a partial equilibrium model which does not include economic developments in other sectors of the economy. This fact might lead to biased results, particularly when significant changes in the price of electricity are expected, in which case it is preferable that significant changes in demand and supply are calculated endogenously by the model.

Another serious limitation is that electricity is assumed to be a homogeneous good. As is well known, electricity demand is not constant but rather is characterised by swings between peak and off-peak periods and significant seasonal differences in demand; hence, the variable economic value attached to electricity. National and international trade are important instruments for levelling the demand and obtaining a more constant and therefore economical utilisation of production capacity.

As a last point, we mention that the possibilities for modelling different institutional arrangements are quite limited. In this article, two extreme cases have been compared: a system of central planning and a free market regime. Policy restrictions are included by defining different sets of alternatives for electricity generation. Although this might be an interesting starting point, it remains quite a rigid method for modelling different institutional arrangements. Further research is needed in order to allow for a greater range of variation within institutional frameworks.

Acknowledgements - The authors would like to thank A.E. Steenge (University of Twente) for his valuable comments on earlier versions of this article.

\section{REFERENCES}

1. Künneke, R. W., The Dutch struggle for a stable institutional framework in the electricity sector, in Competition in the Electricity industry, ed. O. J. Olsen. DJOF Publishing, Copenhagen, 1995.

2. McKinsey and Company, Inc., Verzekeren van een passende elektriciteitsvoorziening voor de toekomst (in Dutch), Amsterdam, 1994.

3. Künneke, R. W., Arentsen, M. J., Manders, A. M.P., Steenge A. E. and Voogt, M. H., Marktwerking in 
de energiesector. Een onderzoek naar de mogelijkheden tot introductie van marktwerking in de Nederlandse energiesector (in Dutch), Research Papers on Energy Policy Studies, Ministry of Economic Affairs, The Hague, The Netherlands, 1996.

4. Arentsen, M. J., Kunneke, R. W. and Moll, H. C., The Dutch electricity reform: reorganisation by negotiations, in European Electricity Systems in Transition, ed. A. Midttun. Elsevier, Amsterdam, 1997.

5. Tweede Kamer, Derde Energienota, vergaderjaar 1995-1996, 24525, nos. 1-2 (Third Energy Policy Note, 1996. Publication of the Second Chamber of the Dutch Parliament), The Hague, The Netherlands, 1996.

6. Bye T. and Johnsen, T. A., Prospects for a common Nordic electricity market, Discussion paper No. 144, Oslo: Statistics, Norway, 1995.

7. Bergman, L., Journal of Policy Modelling, 1990, 12, 67.

8. Jorgenson, D. W. and Wilcoxen, P. J., Journal of Policy Modeling, 1990, $12,71$.

9. Burniaux, J.-M., Martin, J. P., Nicoletti G. and Martins, J. O., GREEN, A multi-sector, multi-region general equilibrium model for quantifying the costs of curbing $\mathrm{CO}_{2}$ emissions: a technical manual. OECD working papers no. 116, Paris, France, 1992.

10. Fishbone, L. G. and Abilock, H., Energy Research, 1981, 5, 35.

11. Kydes, A. S., Energy-The International Journal, 1990, 15, 56.

12. Edmonds, J. and Reilly, J., Energy Economics, 1983, 5(2), 7.

13. Baughman, M. L., Joskow P. L. and Kamat, D. P., Electric Power in the United States: Models and Policy Analysis. MIT Press, Cambridge, MA, 1979.

14. Manne, A. S., ETA-MACRO: A model of energy-economy interactions, in ed. C. J. Hitch, Modelling EnergyEconomy Interaction: Five Approaches. Resources for the Future, Washington, DC, 1977.

15. Manne, A. S. et al., MARKAL-MACRO: a linked model for energy-economy analyses, Department of Energy, New York, 1992.

16. Hoffman, K. C. and Jorgenson, D. W., The Bell Journal of Economics, 1977, 8, 44.

17. Häfele, W., Energy in a Finite World, Vols. 1 and 2. Ballinger, Cambridge, MA, 1981.

18. Kydes, A. S., Minasi M. J. and Hudson, E. A., A new energy-economy system: macro-economic feedback's and linkages, in ed. A. S. Kydes et al, Energy Modelling and Simulation. IMACS/North-Holland, Amsterdam, 1983.

19. N.V. Samenwerkende Elektriciteits-produktiebedrijven, Elektriciteitsplan 1995-2004, Arnhem, The Netherlands, 1994. 